\title{
Pengelolaan Potensi Pariwisata Desa Watu Tiri Dengan Pendekatan Pariwisata Berbasis Masyarakat
}

\author{
Roseven Rudiyanto ${ }^{1)}$, Septian Hutagalung ${ }^{2)}$ \\ Program Studi D3 Ekowisata, Politeknik eLBajo Commodus 1,2) \\ Labuan Bajo, Kabupaten Manggarai Barat, Nusa Tenggara Timur \\ E-mail : roseven@poltekelbajo.ac.id
}

\begin{abstract}
Abstrak
Desa Watu Tiri merupakan sebuah desa di Kabupaten Manggarai Barat yang memiliki potensi alam dan budaya di bidang pariwisata. Akan tetapi, masyarakat lokal masih belum mampu mengelola potensi tersebut dengan baik. Pengelolaan potensi wisata dengan pendekatan pariwisata berbasis masyarakat merupakan instrumen pengembangan masyarakat dalam memperkuat partisipasi dan kemampuan masyarakat lokal untuk mengelola sumber daya pariwisata. Tujuan penelitian ini untuk identifikasi potensi alam dan budaya di Desa Watu Tiri, dan pengelolaannya dengan pendekatan pariwisata berbasis masyarakat. Metode kualitatif dengan teknik pengumpulan data observasi dan forum diskusi merupakan metode yang digunakan dalam penelitian ini. Hasilnya, Desa Watu Tiri memiliki poin-poin penting yang mendukung penerapan pengelolaan potensi wisata dengan pendekatan pariwisata berbasis masyarakat. Namun demikian, pemerintah Desa Watu Tiri masih harus mengerjakan hal yang menghambat penerapan pengelolaan potensi dengan pendekatan tersebut.
\end{abstract}

Kata kunci: pariwisata, pengelolaan, masyarakat

Management of Tourism Potential of Watu Tiri Village by Community-Based Tourism Approach

\begin{abstract}
Watu Tiri is a village in West Manggarai Regency, which has natural and cultural potential in the tourism sector. However, local people are still not able to manage this potential properly. Management of tourism potential with a community-based tourism approach is an instrument of community development in strengthening the participation and ability of local communities to manage tourism resources. The purpose of this research is to identify the natural and cultural potential in Watu Tiri Village, and its management with a community-based tourism approach. Qualitative methods with observation data collection techniques and discussion forums are the methods used in this study. As a result, Watu Tiri Village has important points that support the implementation of tourism potential management with a community-based tourism approach. However, the government of Watu Tiri village still has to do things that hinder the application of potential management with that approach.
\end{abstract}

Keyword: tourism, management, community

\section{PENDAHULUAN}

Desa Watu Tiri secara administrai terletak pada wilayah kecamatan Lembor Selatan, Kabupaten Manggarai Barat, Provinsi Nusa Tenggara Timur. Desa ini memiliki kekayaan alam dan budaya yang berpotensi dijadikan sebagai Daya Tarik Wisata (DTW). Akan tetapi potensi tersebut belum dikelola oleh masyarakat secara maksimal. Ada beberapa faktor yang mempengaruhi belum maksimalnya pengelolaan DTW di Desa Watu Tiri, diantaranya: 1) Masih rendahnya kualitas SDM masyarakat desa. Tingkat pendidikan masyarakat masih didominasi oleh pendidikan dasar. Hanya $2.6 \%$ dari seluruh warga yang menempuh pendidikan tinggi jenjang diploma hingga strata (Kecamatan Lembor Selatan Dalam Angka, 2018); 2) Belum adanya pelatihan yang diadakan untuk meningkatkan kemampuan masyarakat di bidang pariwisata. Padahal, secara geografis, letak desa Watu Tiri sangat strategis, yaitu berada dalam jalur Labuan Bajo - Wae Rebo, dimana Labuan Bajo dan Wae Rebo merupakan destinasi pariwisata internasional.

Pariwisata sendiri memiliki fungsi sebagai penggerakan peningkatan ekonomi 
masyarakat. Bertambahnya lapangan pekerjaan, pertumbuhan pendapatan, dan peningkatan standar hidup merupakan salah satu manfaat pariwisata pada aspek sosial ekonomi (Sharafieva, 2012). Akan tetapi, pada sisi lain pariwisata memiliki dampak terhadap masyarakat. Tefler \& Sharpley (2008) berpendapat bahwa kegiatan pariwisata itu sendiri dapat memiliki dampak pada destinasi, lingkungannya dan masyarakat setempat. Dampak pariwisata tersebut dapat berupa terkikisnya kebudayaan lokal, hilangnya arsitektur lokal, hingga perubahan sumber mata pencaharian (Khandare \& Phophueksanand, 2018). Dengan demikian, pengelolaan DTW di Desa Watu Tiri yang salah, dapat berdampak kepada kehidupan sosial ekonomi masyarakat desa tersebut.

Pengelolaan DTW dengan pendekatan

Pariwisata Berbasis Masyarakat (PBM) merupakan salah satu solusi untuk menghindari dampak negatif dari perkembangan pariwisata. Pariwisata Berbasis Masyarakat (PBM) sendiri adalah model pengelolaan pariwisata yang partisipatif. PBM memiliki tujuan untuk menciptakan manfaat nyata dan adil bagi berbagai pemangku kepentingan, baik di dalam maupun di luar masyarakat (Suansri, 2003). Pengembangan masyarakat dalam memperkuat partisipasi dan kemampuan masyarakat lokal untuk mengelola sumber daya pariwisata, membantu masyarakat lokal dalam menghasilkan pendapatan, mengembangkan ekonomi lokal, melestarikan budaya, melestarikan lingkungan dan menyediakan peluang pendidikan merupakan contoh mafaat nyata dari pengelolaan pariwisata dengan pendekatan PBM (Hamzah \& Khalifah, 2009). Berdasarkan penjelasan sebelumnya, penelitian ini bertujuan untuk mengidentifikasi potensi alam dan budaya di Desa Watu Tiri, dan pengelolaannya dengan pendekatan PBM.

\section{KAJIAN PUSTAKA}

\section{Potensi Pariwisata}

Pendit (1999) menjelaskan bahwa potensi pariwisata suatu daerah dapat dikelompokan 2 jenis, yaitu: a) Potensi wisata alam (natural tourist attractions) adalah segala bentuk daya tarik keadaan fisik yang dimiliki suatu daerah. Seperti sungai, danau, gunung, dan sebagainya; b) Potensi wisata Daya tarik budaya (cultural tourist attractions) adalah segala potensi yang bersumber pada kehidupan sosial masyarakat. Seperti: upacara adat, lagu, tarian.

\section{Pariwisata Berbasis Masyarakat}

Goodwin dan Santili

(2009)

berpendapat bahwa kemunculan PBM didasari atas kegagalannya pendekatan "top-down" untuk kegiatan konservasi dan pembangunan. Pariwisata Berbasis Masyarakat (PBM) merupakan instrumen pengembangan masyarakat dalam memperkuat partisipasi dan kemampuan masyarakat lokal untuk mengelola sumber daya pariwisata (Hamzah \& Khalifah, 2009). Suansri (2003) menjelaskan bahwa pariwisata berbasis masyarakat adalah pariwisata yang dimiliki dan dikelola oleh masyarakat, dimana keuntungannya digunakan untuk kepentingan masyarakat.

ASEAN (2016) merumuskan prinsipprinsip pariwisata berbasis masyarkat, diantaranya: a) Melibatkan dan meberdayakan masyarakat untuk memastikan kepemilikan dan manajemen yang transparan; b) Membangun kemitraan dengan para pemangku kepentingan terkait; c) Mendapatkan pengakuan dengan otoritas terkait; c) Meningkatkan kesejahteraan sosial dan menjaga martabat manusia; d) Memiliki mekanisme pembagian keuntungan yang adil dan transparan; e) Meningkatkan hubungan dengan ekonomi lokal dan regional; f) Menghormati budaya dan tradisi setempat; g) Berkontribusi pada konservasi sumber daya alam; h) Meningkatkan kualitas pengalaman pengunjung dengan memperkuat interaksi tuan rumah dan tamu yang bermakna; dan i) Bekerja menuju swasembada finansial.

Hamzah \& Khalifah (2009) menjelaskan 9 sembilan langkah yang harus dilakukan untuk mengelola pariwisata dengan pendekatan PBM, diantaranya: a) Menilai kebutuhan masyarakat dan kesiapan terhadap pariwisata; b) Mengedukasi dan mempersiapkan komunitas untuk pariwisata; c) Menemukan dan membangun kepemimpinan / local champion; d)Menyiapkan dan mengembangkan organisasi komunitas; e) Mengembangkan kerjasama dengan para pihak terkait; f) Mengadopsi pendekatan yang terintegrasi; g) Merencanakan dan mendesain kualitas produk, h) Mengindentifikasi permintaan pasar dan mengembangkan strategi pemasaran; dan i) Penerapan dan mengamati kinerja pariwisata.

\section{METODE PENELITIAN}

Dalam penelitian ini pengumpulan data dilakukan di Desa Watu Tiri, Kabupaten Manggarai Barat, Provinsi Nusa Tenggara Timur. Desa Watu Tiri dinilai oleh peneliti memiliki potensi wisata yang bisa 
dikembangkan, dan masyarakat desa tersebut siap menerapkan pengelolan pariwisata berbasis masyarakat. Selain itu, Desa Watu Tiri telah ditetapkan sebagai salah satu desa wisata di wilayah Kabupaten Manggarai Barat melalui surat keputusan bupati manggarai barat juga menjadi alasan penetapan lokasi penelitian. Ruang lingkup penelitian ini adalah potensi wisata yang ada di desa Watu Tiri dan pengelolaan potensi tersebut dengan pendekatan pariwisata berbasis masyakarat.

$$
\text { Penelitian ini menggunakan }
$$

pendekatan kualitatif, dimana proses berpikir penelitian secara induktif untuk menangkap fakta dan fenomena-fenomena sosial yang terjadi di lapangan melalui pengamatan (Nugrahani, 2014). Teknik pengumpulan data yang digunakan dalam penelitian ini adalah focus group discussion (FGD) dan observasi. Pada focus group discussion peneliti mengundang kepala desa berserta perangkat desa, tokoh masyarakat, tokoh adat, dan perwakilan sanggar budaya sebagai informan. Ada 4 hal yang menjadi tema dalam FGD bersama para informan, yaitu 1) potensi pariwisata yang ada di desa, 2) kelompok masyarakat yang sudah terbentuk, 3) permasalahan yang dihadapi oleh masyarakat dalam mengembangkan pariwisata, dan 4) harapan dan cita-cita yang ingin dicapai melalui pengembangan pariwisata di Desa Watu Tiri.

Pada proses observasi, peneliti mengunjungi lokasi penelitian dengan tujuan mengetahui topografi Desa Watu Tiri. Datadata yang terkumpul melalui FGD dan observasi menjadi data primer pada peneltian ini, sedangkan data sekunder penelitian ini adalah website desa, dokumen, dan hasil studi terkait Desa Watu Tiri.

\section{HASIL DAN PEMBAHASAN}

\section{Profil Desa Watu Tiri}

Desa Watu Tiri merupakan sebuah desa yang terletak di bagian barat Pulau Flores. Dari Labuan Bajo, desa ini dapat ditempuh dengan waktu 2 jam 30 menit dengan jarak kurang lebih $88 \mathrm{~km}$. Berdasarkan surat keputusan yang dikeluarkan oleh bupati Manggarai Barat, Desa Watu Tiri telah ditetapkan sebagai desa wisata. Luas wilayah Desa Watu Tiri adalah $1.555 \mathrm{~km} 2$ atau 1803 hektar (ha), dimana 890 hektar atau 49,3\% lahannya digunakan untuk pemukiman warga (RPJMDes Watu Tiri 2019 - 2024). Dijelaskan lebih lanjut, desa ini memiliki jumlah masyarakat $420 \mathrm{KK}$ atau 2113 jiwa. Topografi kawasan Desa Watu Tiri sangat beragam, dari dataran tinggi yang merupakan bagian dari kaki Gunung Surunumbeng, hingga kawasan pantai.

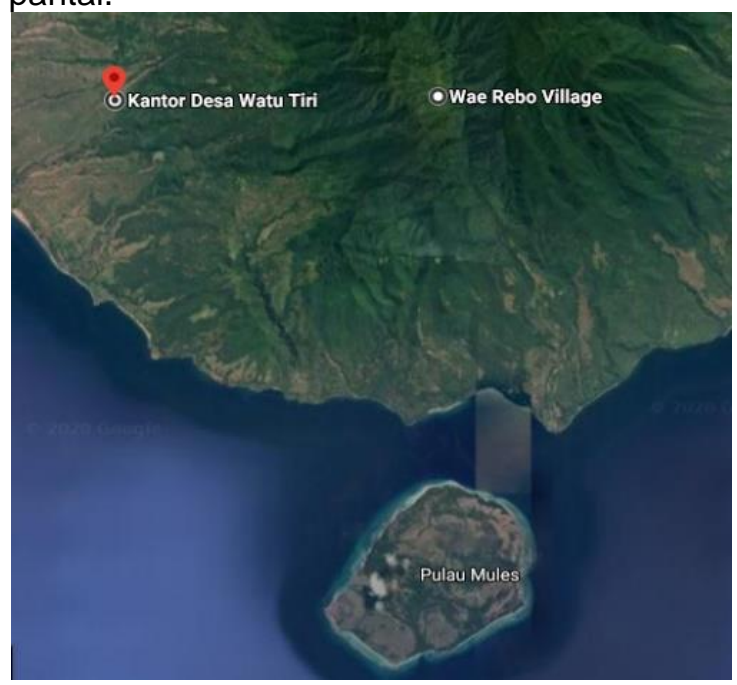

Sumber: Google Maps (2021)

Gambar 1. Letak Kantor Desa Watu Tiri

\section{Hasil Focus Group Discussion (FGD) \\ Potensi dan atraksi wisata alam}

Potensi dan atraksi wisata alam yang terdapat di Desa Watu Tiri, yaitu 1) Pantai pasir putih Mberenang. Pantai Mberenang merupakan kawasan yang termasuk dalam Taman Nasional Perairan (TNP) Laut Sawu (Kementerian Kelautan dan Perikanan, 2020). Kegiatan pariwisata yang bisa dilakukan pada beragam, diantaranya adalah dari kegiatan olahraga seperti berenang, dan surfing (karena ombak pantai ini cukup deras dan tinggi), menikmati sunset, hingga kawasan ini bisa dijadikan tempat konservasi penyu. Hal ini disampaikan oleh para penduduk bahwa penyu kerap muncul untuk bertelur di pantai pada bulan mei hingga juli. Selain itu, kegiatan camping bisa dilakukan di pantai ini. 2) Sumber mata air panas, dimana para turis bisa mandi menggunakan air panas yang secara alami muncul.

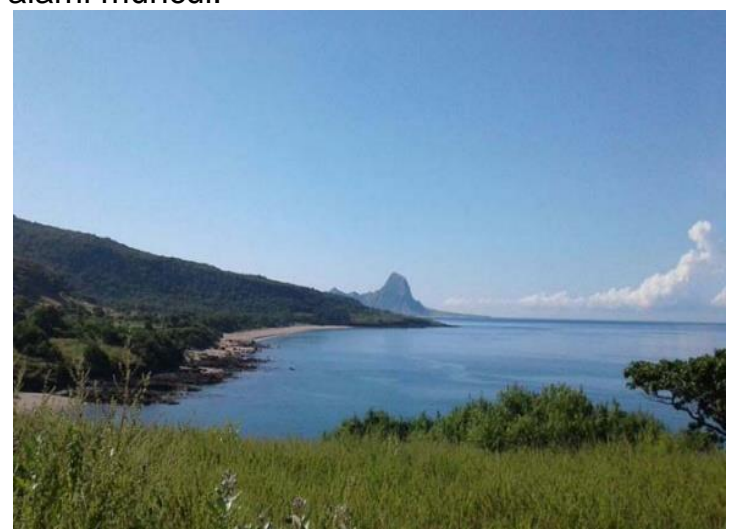

Sumber: manggaraibaratkab.go.id (2021)

Gambar 2. Letak Kantor Desa Watu Tiri 
Desa Watu Tiri juga terdapat potensi dan atraksi wisata buatan manusia, diantaranya 1) kegiatan ibu-ibu menenun kain songke. Ibu-ibu masyarakat desa ini mengisi waktu luang dengan menenun kain songke; 2) Upacara Penti. Upacara tahun baru untuk mengungkapka rasa syukur kepada Tuhan dan para leluhur karena telah diberikan kesehatan dan hasil pertanian selama satu tahun terakhir. Biasanya upacara ini dilakukan di antara bulan desember hingga januari; 3) Upacara Mareng, merupakan upacara meminta hujan agar hasil pertanian baik; 4) Upacara penyambutan secara adat di rumah gendang.

\section{Kelompok Masyarakat Desa Watu Tiri}

Desa Watu Tiri telah memiliki beberapa komunitas masyarakat, diantaranya Sanggar Budaya Sangkulering, kelompok sadar wisata (pokdarwis) Desa Watu Tiri, perkumpulan ibu-ibu pengrajin tenun, dan Badan Usaha Milik Desa (BUMDes). Desa Watu Tiri memproyeksikan BUMDes sebagai organisasi yang menaungi seluruh pengelolaan potensi wisata desa.

\section{Permasalahan Yang Dihadapi}

Beberapa permasalahan yang dihadapi oleh dalam pengelolaan DTW di Desa Watu Tiri, diantaranya: (1) Rendahnya SDM masyarakat Desa Wisata; (2) Aksesbilitas dan Amenitas yang belum memadai. Kondisi jalan yang rusak dan belum tersedianya homestay di Desa Watu Tiri; (3) Belum terdokumentasikannya narasi DTW alam dan budaya; (4) Adanya citra negatif yang terkait dengan hal mistis dimiliki oleh Pantai Mberenang.

\section{Harapan dan Cita-cita Masyarakat Desa Watu Tiri}

Beberapa harapan dan cita-cita yang dimiliki oleh Desa Watu Tiri, diantaranya: (1) Adanya peningkatan perekonomian masyarakat desa melalu pariwisata; (2) Masyarakat desa mendapatkan pelatihan dan pendampingan dalam pengelolaan pariwisata; (3) Regulasi dari pemerintah daerah mengenai sistem pengelolaan pariwisata di Desa Watu Tiri.

\section{Pendekatan Pariwisata Berbasis Masyarakat (PBM) Di Desa Watu Tiri}

Berdasarkan hasil FGD dan observasi, maka dapat dilakukan dengan sembilan langkah pendekatan Pariwisata Berbasis Masyarakat (PBM) dalam pengelolaan DTW di Desa Watu Tiri, yaitu:
Menilai kebutuhan masyarakat dan kesiapan terhadap pariwisata. Dalam pengelolaan pariwisatanya, Desa Watu Tiri membutuhkan fasilitas-fasilitas umum, diantaranya listrik, akses jalan yang harus diperbaiki, amenitas pendukung pariwisata seperti wc atau kamar ganti di tepi pantai, dan kios untuk menawarkan produk lokal (makanan, hasil kebun, atau suvenir), serta homestay. Masyarakat Desa Watu Tiri telah memiliki pandangan bahwa pariwisata bisa menjadi solusi untuk meningkatkan perekonomian lokal, sekaligus sebagai sarana pelestarian kearifan lokal. Namun demikian, masyarakat sadar bahwa kualitas SDM di bidang pariwisata harus ditingkatkan, seperti ketersediaan pemandu lokal dengan kemampuan bahasa asing yang baik.

Mengedukasi dan mempersiapkan masyarakat Desa Watu Tiri untuk pariwisata. Pengertian pariwisata secara umum telah dimengerti oleh masyarakat, namun edukasi mengenai pariwisata berbasis masyarakat masih perlu diselenggarakan. Selain itu, Desa Watu Tiri perlu mengadakan pelatihan kemampuan dasar kepariwisataan, seperti kemampuan berbahasa asing dan pemasaran. $\mathrm{Hal}$ ini merupakan upaya nyata untuk meningkatkan kualitas SDM masyarakat desa. Menemukan dan membangun kepemimpinan lokal/local champion. Perangkat pemerintah desa cenderung berusia muda, yaitu 19 - 40 tahun. Hal ini bisa menjadi faktor yang memudahkan untuk menemukan dan membangun karakter local champion. Selain itu, ketersediaan sekolah menengah kejuruan di desa ini juga bisa menjadi sarana untuk memperkenalkan pariwisata kepada golongan muda.

Menyiapkan dan mengembangkan organisasi masyarakat. Seperti yang disampaikan sebelumnya, bahwa di Desa Watu Tiri sudah terdapat organisasi masyarakat. Namun demikian, tidak adanya program kerja yang berkelanjutan menjadi permasalahan yang dihadapi oleh seluruh organisasi masyarakat di desa tersebut.

Mengembangkan kerjasama Desa Watu Tiri dengan para pihak terkait. Pada saat ini, Desa Watu Tiri belum memiliki kerja sama di bidang pariwisata. Akan tetapi, penetapan Desa Watu Tiri sebagai salah satu desa wisata di Kabupaten Manggarai Barat merupakan langkah awal untuk menjalin kerjasama dengan para stakeholder, seperti Dinas Pariwisata Kabupaten Manggarai Barat, Badan Otoritas Pariwisata Labuan Bajo Flores, Lembaga Swadaya Masyarakat, dan institusi pendidikan tinggi di Kabupaten Manggarai 
Barat. Bentuk kerja sama tersebut bisa diwujudkan dalam pelatihan dan pemantuan pengelolaan potensi wisata oleh masyarakat.

Mengadopsi pendekatan yang terintegrasi. Potensi konservasi penyu bisa menjadi pendekatan terintegrasi antara pariwisata dan semangat konservasi lingkungan. Terintegrasinya konservasi dan pariwisata bisa menjadi paket wisata yang dapat ditawarkan oleh para turis.

Merencanakan dan mendesain kualitas produk. Pada saat ini Desa Watu Tiri masih belum memiliki program paket wisata yang bisa ditawarkan kepada turis. Perlu diadakannya forum diskusi antara pemerintah tingkat desa dan kecamatan bersama tokoh masyarakat dengan para mitra kerja sama untuk mematenkan paket wisata Desa Watu Tiri.

Mengindentifikasi permintaan pasar dan mengembangkan strategi pemasaran. Berdasarkan potensi dan karakteristiknya, segmen turis yang bisa dijadikan sebagai sasaran paket wisata Desa Watu Tiri adalah ecotourist atau green tourist. Ecotourist merupakan segmen turis yang menaruh perhatian terhadap kelestarian alam, dan biasanya berada dalam kelompok umur 20 40 tahun (Beeton, 1998). Selain itu, keberadaan situs resmi desa yaitu www.desawatutiri.com, yang mana bisa menjadi sarana promosi secara digital. Situs ini bisa menarasikan objek serta kegiatan wisata yang bisa dilakukan oleh para turis. Pemerintah desa juga bisa menjalin kerja sama dengan para travel agent untuk memasukan Desa Watu Tiri sebagai destinasi dalam paket yang ditawarkan.

Penerapan dan mengamati kinerja pariwisata. Untuk proses penerapan dan pengamatan kinerja, Pemerintah Desa Watu Tiri bisa menjalin kerja sama guna mendapatkan fasilitator. Fasilitator bisa berasal dari para pemangku kepentingan, seperti dinas pariwisata, institusi pendidikan, LSM, dan sebagainya. Pengamatan dan evaluasi secara regular berfungsi meningkatkan kinerja dan kualitas produk yang ditawarkan. Kegiatan pengamatan dan evaluasi tersebut harus ditulis sebagai laporan kinerja sekaligus menjadi dokumen pengelolaan.

\section{PENUTUP}

Desa Watu Tiri memiliki potensi besar dalam pariwisata, yaitu potensi alam dan budaya. Untuk menjalankan pengelolaan potensi wisata dengan pendekatan pariwisata berbasis masyarakat, Desa Watu Tiri telah memiliki beberapa aspek yang menjadi modal dasar penerapannya, diantarnya: a) Masyarakat telah mengerti peran pariwisata sebagai alat untuk meningkatkan ekonomi lokal, b) Perangkat pemerintah desa cenderung berusia muda dan terdapatnya SMK pariwisata bisa menjadi faktor yang mempermudah pengidentifikasian local champion, c) Telah terbentuknya kelompok masyarakat dan BUMDes yang diproyeksikan sebagai pengelola destinasi, d) Adanya situs resmi desa yang bisa menjadi sarana promosi www.desawatutiri.com.

Peneliti menyarankan agar penelitian selanjutnya dapat mengidentifikasi faktorfaktor apa saja yang mempengaruhi keberhasilan pengelolaan potensi daya tarik wisata dengan pendekatan Pariwisata Berbasis Masyarakat (PBM). Selain itu, perlu adanya kajian mendalam mengenai karakteristik ombak terhadap atraksi olahraga air, seperti surfing dan peluang konservasi penyu Pantai Mberenang.

\section{DAFTAR PUSTAKA}

Hamzah, A., \& Khalifah, Z. (2009). Handbook on Community Based Tourism: How to Develop and Sustain CBT. Kuala Lumpur: APEC Secretariat.

Suansri, P. (2003). Community Based Tourism Handbook. Bangkok: Mild Publishing.

ASEAN. (2016). ASEAN Community Based Tourism Standard. Jakarta: ASEAN Secretariat.

Pendit, N., S. (1999). Wisata Konvensi, Potensi Gede Bisnis Besar. Jakarta: PT. Gramedia

Nugrahani, F. (2014). Metode Penelitian Kualitatif. Solo: Cakra Books.

Pemerintah Desa Watu Tiri. (2019). Rancangan Pembangunan Jangka Menengah Desa Watu Tiri.

Beeton, S. (1998). Ecotourism: A Practical Guide for Rural Communities. Colling Wood: Landlink Press.

Kementerian Kelautan dan Perikanan. Profil Kawasan Konservasi Perairan Nasional:Taman Nasional Perairan Laut Sawu Dan sekitarnya di Provinsi Nusa Tenggara Timur di https://kkp.go.id/djprl/bkkpnkupang/pa ge/352-profil-tnp-laut-sawu. (diakses 20 Juli 2020).

Badan Pusat Statistik Manggarai Barat. (2018). Kecamatan Lembor Selatan Dalam Angka. Kabupaten Manggarai Barat: BPS Manggarai Barat. 
Sharafieva, D. R. (2012). Funktsii turizma $v$ sotsialno ekonomicheskoy structure obschestva. Известия Казанского государственного архитектурностроительного университета, $\quad(4$ (22)), 78-86.

Telfer, D. \& R. Sharpley. (2008). Tourism and Development in the Developing World. London: Routledge.

Khandare, V., and Phophueksanand, P. (2018). Social and Cultural Impact of Tourism Development in Thailand.
International Journal of Research in Economics and Social Sciences, 8

Goodwin, H., \& Santilli, R. (2009). Communitybased tourism: a success?. ICRT Occasional Paper 2009 No.OP11 pp.37 pp. Leeds: International Centre for Responsible Tourism, Leeds Metropolitan University. 